\title{
Proposed simple electro-mechanical automotive speed control system
}

\author{
Ahmed Farouk AbdelGawad ${ }^{1, *}$, Talal Saleh Mandourah ${ }^{2}$ \\ ${ }^{1}$ Professor of Computational Fluid Mechanics, Mech. Eng. Dept., Umm Al-Qura Univ., Makkah, Saudi Arabia \\ ${ }^{2}$ Mech. Eng. Dept., Umm Al-Qura Univ., Makkah, Saudi Arabia \\ Email address: \\ afaroukg@yahoo.com (A. F. AbdelGawad)
}

\section{To cite this article:}

Ahmed Farouk AbdelGawad, Talal Saleh Mandourah. Proposed Simple Electro-Mechanical Automotive Speed Control System. American Journal of Aerospace Engineering. Special Issue: Hands-on Learning Technique for Multidisciplinary Engineering Education.

Vol. 2, No. 1-1, 2015, pp. 1-10. doi: 10.11648/j.ajae.s.2015020101.11

\begin{abstract}
Millions of people are killed or seriously injured on the roads due to terrified accidents every year. Most of these accidents are attributed to the over-speeding of the road vehicles. Thus, the road speed limiter $(R S L)$ is a very important technique to reduce the possibility of road accidents. An interesting idea to control the speed of the vehicle is to apply electronic control of the air-supply that enters the vehicle carburetor according to road transmitters that are connected and operated either by local network or satellite. In the present paper, a control system was designed and implemented. It is consisted of a control mechanism and an electronic circuit to control the air-inlet to the carburetor according to pre-set programming based on the vehicle speed. Although, it is a challenging job to design and implement modifications to existing systems, the present speed control system was successfully implemented and tested. The present proposed mechanism is simple, inexpensive and suitable to be implemented in developing countries where a big number of cars still work using the traditional carburetor mechanism.
\end{abstract}

Keywords: Road Speed Limiter, Control Mechanism, Electronic Circuit, Car Carburetor

\section{Introduction}

Every six seconds, someone is killed or seriously injured on the world's roads due to horrible accidents. With 1.3 million road deaths each year, this is a global epidemic comparable to Malaria or Tuberculosis. And like those killer diseases, road crashes prey on the young, the poor and the vulnerable. Yet by comparison to other global killers, road injury is utterly neglected [1]. The main reason for these accidents is the high-speed driving. So, the question is how to enforce the moving vehicle to follow the speed limit. This speed limit changes according to the location, topography, weather, cultural standards, etc.

An interesting idea to control the speed of the vehicle is to apply electronic control of the air-supply that enters the vehicle carburetor. An integrated control circuit may be designed and implemented to control the air-inlet to the carburetor according to road transmitters and operated either by road network or satellite. So, the road is to be divided according to the speed limit of the vehicle running on it as desired. This may occur by using a transmission device that is put on the beginning of the road. This device sends signal to the receiver device that is inserted in the car. Then, the receiver takes this signal and translates it to a suitable mechanism to fix a new limit for the speed of the vehicle. The transmitter can be replaced by a satellite receiver.

The main idea of this research is to control the speed of the vehicle during its running along the high-speed roads by the control of the inlet air-flow that enters the vehicle carburetor. An integrated control circuit was designed and implemented. This circuit controls the air-inlet to the carburetor according to pre-set programming based on the vehicle speed. A mechanism was added to control the carburetor-opening using an electrical motor according to the required signal, which is received from the control circuit. The electrical motor rotates a pulley to take a new position according to the control signal and limits the movement of the carburetor throttle arm.

\section{Previous Investigations}

The problem of automotive speed control was considered by many investigators and researchers. Most of the research work concentrated on the impact of the speed limitation on the reduction of accidents and causalities. Few scientific publications are available that concern the technical aspects 
of the speed control system. The following paragraphs give a quick summary of the important previous publications.

Some of the publications handled the technical perspectives of the automotive speed control systems in the recent few years.

Paine [2] presented a classification of speed limitation devices showing the advantages and disadvantages of each type. He found that properly designed ISA (Intelligent Speed Assistance) systems can be highly effective in encouraging motorists to obey speed limits and should be encouraged by governments. Pérez et al. [3] presented a new Infrastructure to Vehicles (I2V) communication and control system for intelligent speed control, which is based upon Radio Frequency Identification (RFID) technology for identification of traffic signals on the road. Their results suggested that an automatic intelligent speed control system can be used to prevent any unexpected traffic circumstances and improve the safety of the occupants of the vehicle. Kameswari et al. [4] presented a design to control the speed of the automobiles at remote places for fixed time. Their proposed model used a microcontroller unit that receives the pedal position and then transfers appropriate signal to the Electronic Control Unit $(E C U)$ that in turn controls the automobiles' throttle position. They stated that their theoretical study needs further extension to consider more than one vehicle.

In the early seventies of the past century, Ford Motor Company assigned patents concerning maximum vehicle speed limiter for a vehicle that has a pedal connected to a carburetor throttle valve through a linkage means $[5,6,7]$. The patents were based on mechanical and/or electromagnetic-circuit systems. Other inventors produced patents for engine maximum speed limiter with operator control. The control may be carried out by setting the upper limit of engine speed and then not be exceeded once a key-operated switch has been activated to an "off" position [8]. Other method of control can be applied by a programmable device that interfaces with the vehicle and identifies the operator who is allowed to set the maximum speed limit $[9,10]$.

Some researchers discussed the impact of speed limit on the reduction of crashes and pedestrian fatalities in city of Zurich [11], South Australia [12], USA [13] and India [14]. Comte [15] described a driving simulator experiment using The University of Leeds Advanced Driving Simulator to test two speed control systems against an advisory system and a baseline control (no system). His results indicated that there are safety benefits of control systems including a reduction of maximum speed, speed variance and inappropriate speed at hazardous locations.

Safety impacts of speed limiter installations on commercial vehicles; trucks and buses were investigated by some authors.

The experience of national speed-limit legislation [16] and the assessment of the safety efficiency of speed limiters [17] were reported for Australia, Europe and North America. Very recently, Hanowski et al. [18] objected to identify the impacts of implementing road speed limiters (RSL) in commercial vehicle fleet operations. Their study included data from 20 truck fleets, approximately 138,000 trucks, and analyzed more than 15,000 crashes. Their findings showed strong positive benefits for RSLs and that the cost of the technology is negligible and would not be expected to be cost-prohibitive for fleets/owners.

The acceptance of intelligent speed adaptation by car drivers was also concerned by some researchers.

Field trials with in-car speed limiter were reported by Mäkinen and Várhelyi [19, 20]. Their investigations covered three European countries, the Netherlands, Spain and Sweden representing different regions and driving cultures. They concluded that the majority of the drivers accepted the speed limiter as a driver operated system. Also, Duynstee and Katteler [21] discussed the public acceptance of a trial involving Intelligent Speed Adaptation (ISA) for passenger cars in an urban area in the Netherlands for a one-year period. Their test results showed substantial public support for ISA. Abraham [22] analyzed speed data from Ontario highways using the standards of the Institute of Transportation Engineers and proved that the speed limits on these highways should be increased. He also stated that in order to implement the new speed limits, a public education campaign is recommended that would educate road users to reserve the left lane for passing, and to restrict the left lane to mature drivers who have several years of road experience.

\section{Road Speed Limiter (RSL)}

A Road Speed Limiter ( $R S L$ ) means a device whose primary function is to control the fuel feed to the engine, in order to limit the vehicle speed to a preset value, Fig. 1.

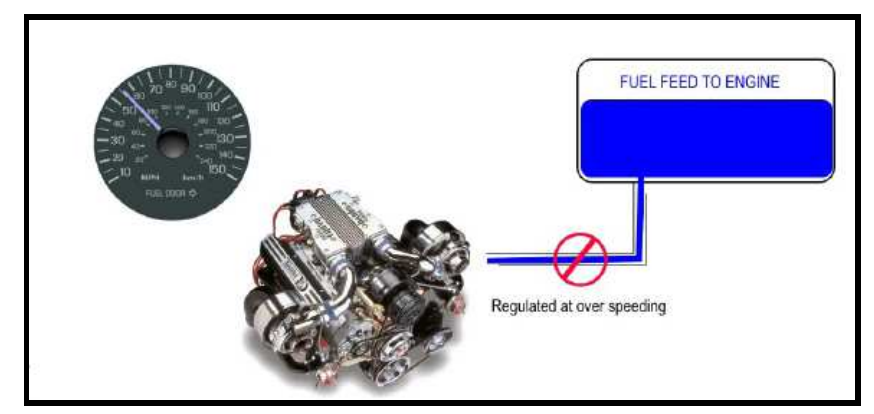

Fig 1. Description of the function of the road speed limiter (RSL) [23].

\subsection{Types of Road Speed Limiter (RSL)}

There are many types of speed limiters. These types may be classified according to either the technique of applying the speed control or the functionality of the speed limiter.

\subsubsection{Types of Road Speed Limiter (RSL) Based on the Control Technique}

(1) Accelerator control

(2) It is also known as the "Cable Type", Fig. 2. The idea of this type is adopted in the present investigation.

(3) Direct fuel control (solenoid valve type) 
(4) Electronic pedal control (for electronic accelerators)

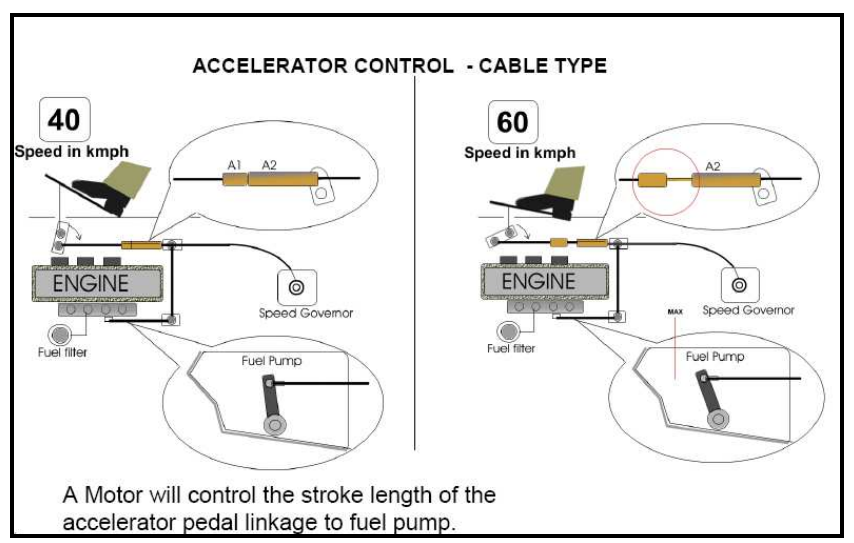

Fig 2. Description of the accelerator control (cable type) [23].

\subsubsection{Types of Road Speed Limiter (RSL) Based on the Functionality [22]}

(1) Top-speed limiting

It prevents the vehicle from exceeding a set speed. Most modern vehicle engine-management systems have a top speed setting but it is usually well in-excess of maximum national speed limits and could not be regarded as a safety device.

(2) Speed alarm set by the driver

It alerts the driver if a selected speed is exceeded. Some vehicles have this feature.

(3) Speed limiter set by the driver

It prevents the vehicle from exceeding the selected speed, except for temporary over-ride situations (e.g., "kick-down" of accelerator pedal). A few vehicle models have this feature (e.g., Renault Megane). These are also known as "Adjustable Speed Limitation Function $(A S L F) "$.

(4) Intelligent speed alarm

The system "knows" the speed limit of the current section of road and direction of travel and alerts the driver if that speed is exceeded by an audible alarm, a visual signal or a vibrating throttle pedal or a combination of these.

(5) Intelligent speed limiter

The system "knows" the speed limit of the current section of road and direction of travel and prevents the vehicle from being accelerated beyond this speed.

\subsection{Limitations of Manually-Set Road Speed Limiter (RSL)}

Systems that require the driver to manually set the speed have several limitations, namely:

(1) They assume that the driver knows the speed limit or can decide a "safe" speed. Actually, in both situations the driver can be in serious error.

(2) The task of setting the speed is tedious and may be distracting.

(3) In practice, these voluntary systems are unlikely to be used on a regular basis.

\subsection{Examples of Automatically-Set Road Speed Limiter (RSL)}

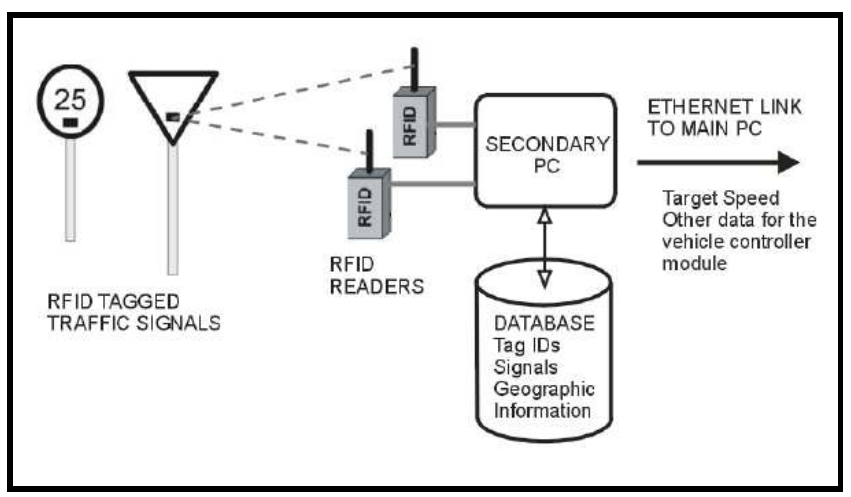

Fig 3. Operational block diagram of the RFID subsystem [3].

(1) First example [3]

It is an intelligent speed controller that is based upon Radio Frequency Identification (RFID) technology for identification of the traffic signals on the road. The operation of the RFID subsystem onboard the vehicle is described with the block diagram of Fig. 3.

The proposed architecture of Ref. [3] for cruise control is shown in Fig. 4. It comprises two parts: placement of RFID sensors (tags) in the road's traffic signals, and the on-board systems in the vehicle.

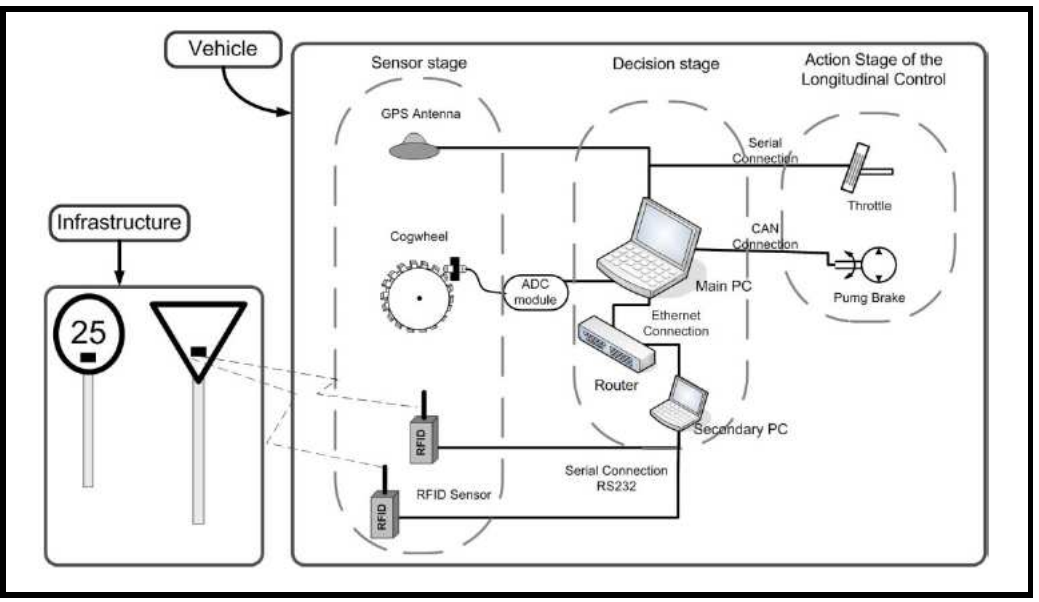

Fig 4. Control scheme onboard the vehicle and its interaction with the infrastructure [3]. 
(2) Second example [4]

A microcontroller unit was used to receive the pedal position from the corresponding sensor, Fig. 5. Then, the microcontroller unit transfers appropriate signal to the Electronic Control Unit $(E C U)$ that in turn controls the automobiles' throttle position, Fig. 6. The microcontroller unit can also interface with a wireless module that is capable of detecting any other transceiver through radio frequency $(R F)$ signals.

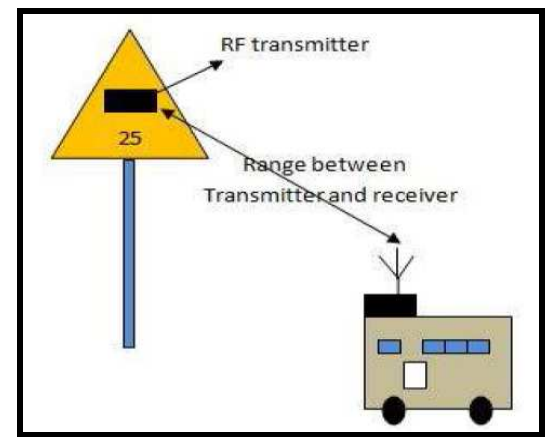

Fig 5. Traffic-signal-posts equipped with RF transmitter (left side) and automobile equipped with $R F$ receiver (right side) [4].

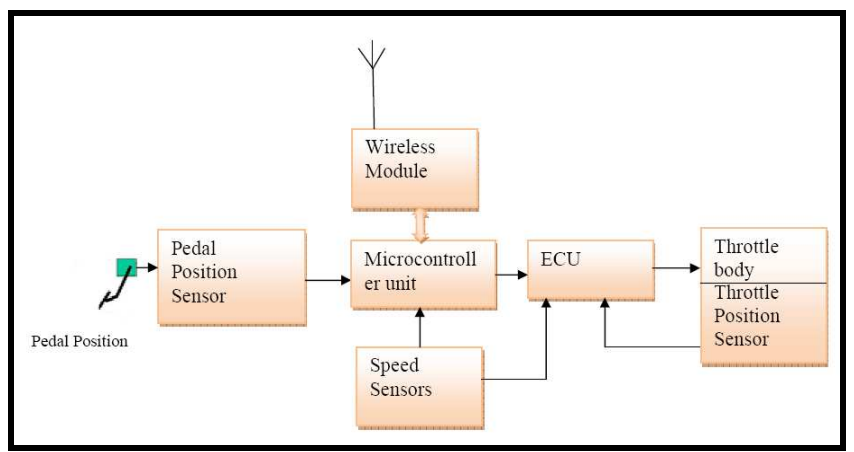

Fig 6. Hard scheme of automobile control system [4].

\section{Present Proposed Speed Limiter Model}

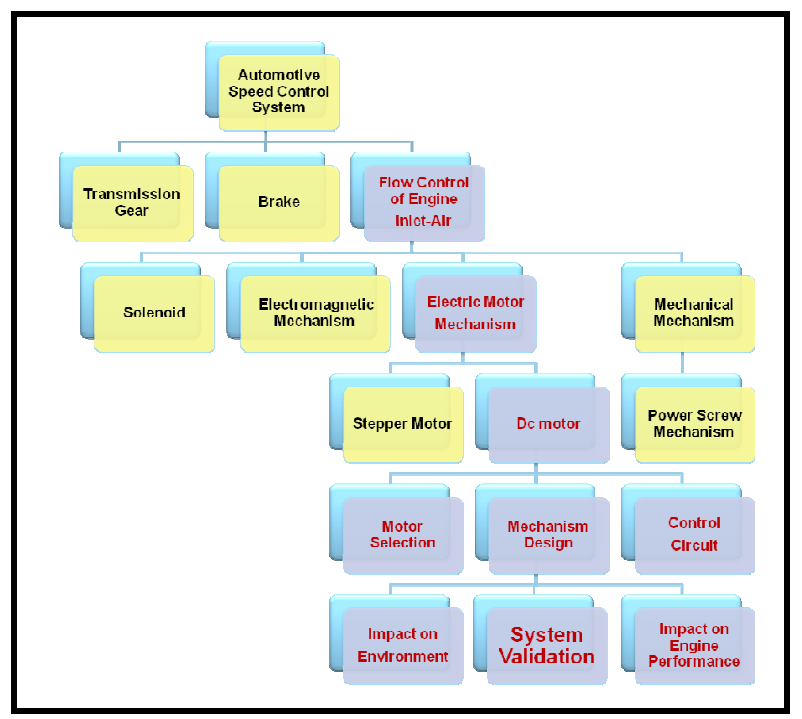

Fig 7. Main ideas of automotive speed control systems.
Based on the two examples of RSL that are shown in Sec. 3.3 , we adopted the general idea to propose a much simpler and less-expensive RSL. Before carrying out the present speed limiter, we had to survey the available techniques for speed control and choose the promising technique from our point of view. Main ideas about automotive speed control systems are shown in Fig. 7. The blocks in "red" are adopted in the present speed limiter model.

\subsection{Engine Specifications of the Present Work}

The main specifications of the engine that was used in the present investigation are listed in table (1).

Figure 8 illustrates the main components of the present investigated engine.

Table 1. Main specifications of the present engine.

\begin{tabular}{ll}
\hline Item & Specifications \\
\hline Type & Four-stroke, Two valves per cylinder \\
Bore $\times$ stroke & $85.00 \mathrm{~mm} \times 70.00 \mathrm{~mm}$ \\
Bore / stroke ratio & 1.21 \\
Displacement & $1588 \mathrm{~cm} 3(96.90 \mathrm{in} 3)$ \\
Compression ratio & 9 \\
Fuel system & One air carburetor \\
Max. output & $55.9 \mathrm{~kW}$ at $5200 \mathrm{rpm}$ \\
Max. torque & $115 \mathrm{Nm}$ at $3800 \mathrm{rpm}$ \\
Coolant & Water \\
\hline
\end{tabular}

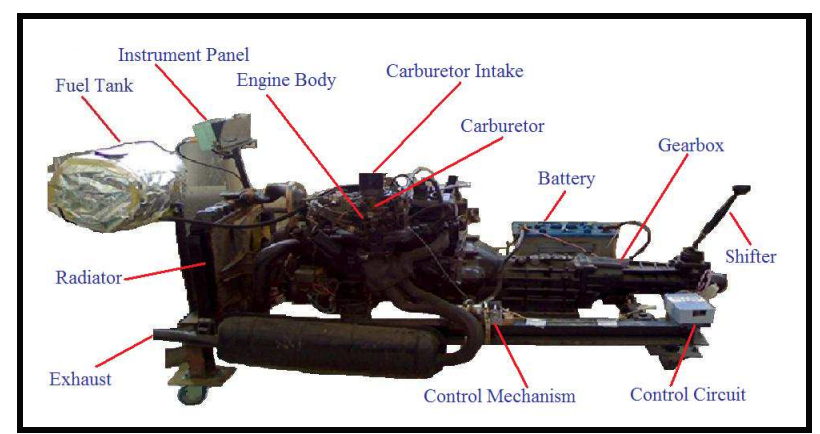

Fig 8. Main components of the present investigated engine.

\subsection{Accelerator System}

\subsubsection{Carburetor}

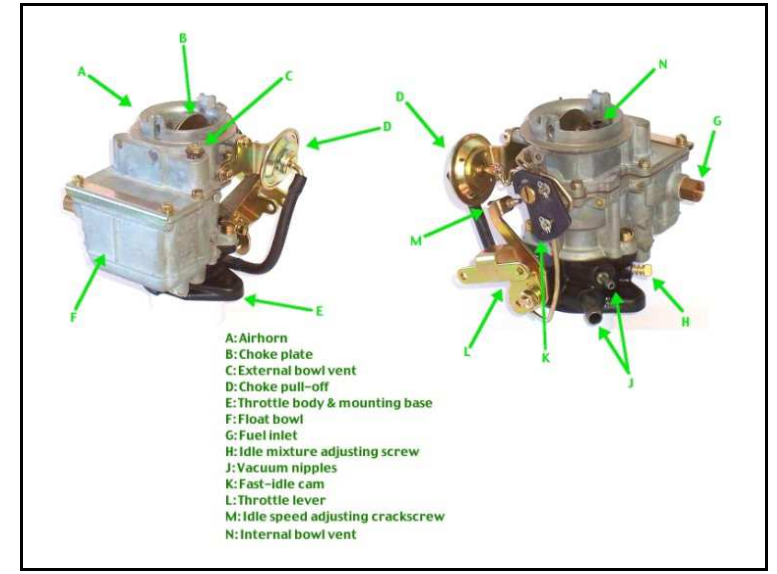

Fig 9. Main parts of the carburetor [24]. 
A carburetor is basically a device for mixing air and fuel in the correct amounts for efficient combustion. It is a network of passages and related parts that help control the air-fuel ratio under specific engine-operating conditions. Figure 9 shows the main parts of a conventional carburetor. The carburetor bolts to the engine intake manifold. The air cleaner (filter) fits over the top of the carburetor to trap dust and dirt.

\subsubsection{Throttle Arm}

Figure 10 demonstrates the throttle arm that controls the opening of the carburetor of the present engine. The accelerator steel wire transmits the mechanical signal of the accelerator pedal to the throttle arm. The present speed limiter model is based on resisting the response (rotation) of the throttle arm to the signal of the accelerator pedal. This resistance is applied by a suitable mechanism that obeys the signal of an electronic circuit according to the permissible speed limit.

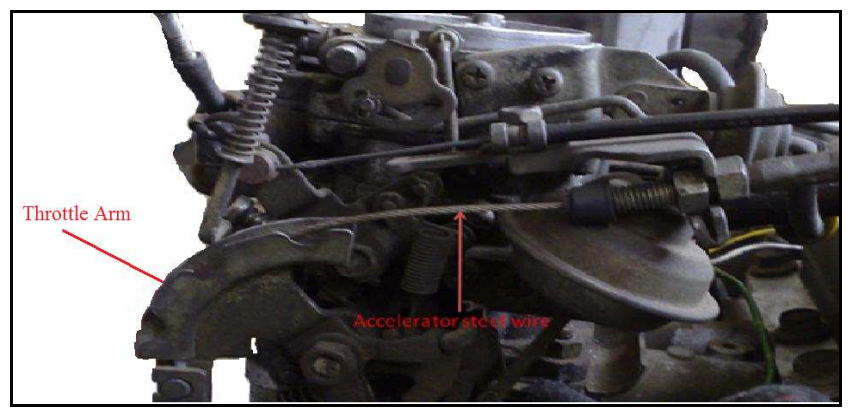

Fig 10. Throttle arm of the carburetor of the present engine.

\subsection{Speed Calibration}

As the engine was not really operating a vehicle, the testing of the validation of the speed limiter was based on the rotational speed of the engine $(R P M)$. Thus, there was a real need to carry out a calibration procedure to relate the rotational speed of the engine to the readings of the speedometer, which reads the corresponding speed of the vehicle $(\mathrm{km} / \mathrm{h})$. Figure 11 shows the used arrangement of the speedometer and the reader of the engine rotational speed (RPM).

The calibration was carried out in a special workshop with a suitable facility using a real car.

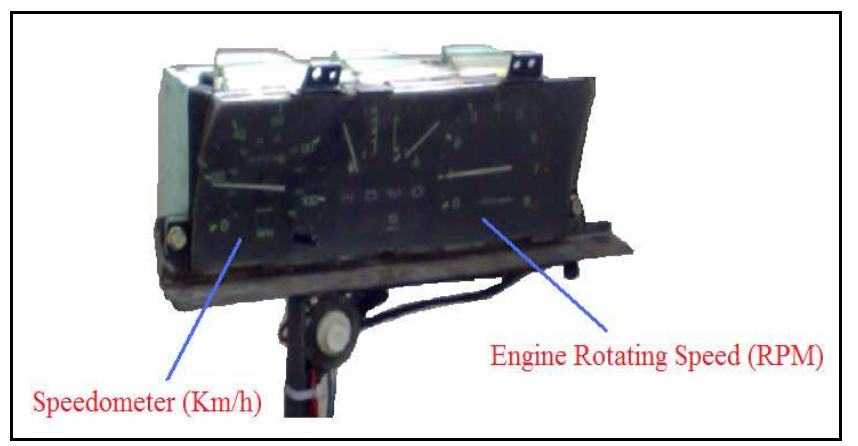

Fig 11. Arrangement of speedometer and reader of the engine rotational speed.
Table (2) illustrates the results of the calibration process. These results were used for the adjustment of the control mechanism as well as the programming of the control circuit.

To ease the control process, eight values of the vehicle speed $(\mathrm{km} / \mathrm{h})$ were selected and the corresponding values of the engine rotational speed $(R P M)$ were recorded. The values that appear in table (2) are average values.

Table 2. Results of the calibration process

\begin{tabular}{lll}
\hline Stage No. & Engine speed $(\boldsymbol{R P M})$ & Vehicle speed $(\boldsymbol{K m} / \boldsymbol{h})$ \\
\hline 1 & 500 & 20 \\
2 & 1000 & 30 \\
3 & 1500 & 40 \\
4 & 2000 & 55 \\
5 & 2500 & 70 \\
6 & 3000 & 80 \\
7 & 3500 & 105 \\
8 & 4000 & 110 \\
\hline
\end{tabular}

\subsection{Force Measurement}

For proper design and application of the control mechanism, the force required to resist the pulling of the accelerator cable must be estimated at every stage of table (2). Thus, the vehicle speed can be limited by preventing excess opening of the carburetor. As shown in Fig. 12, a spring balance was hooked to the throttle arm to measure the resistance force $\left(F_{r}\right)$. These values of resistance force $\left(F_{r}\right)$ were used to design the control mechanism and program the control circuit.

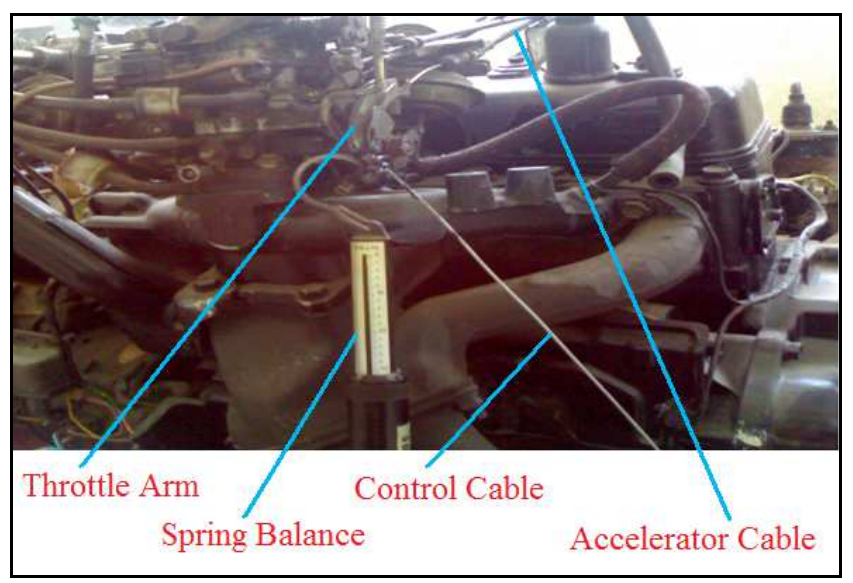

Fig 12. Measurement of the control force using a spring balance.

\subsection{Control Mechanism}

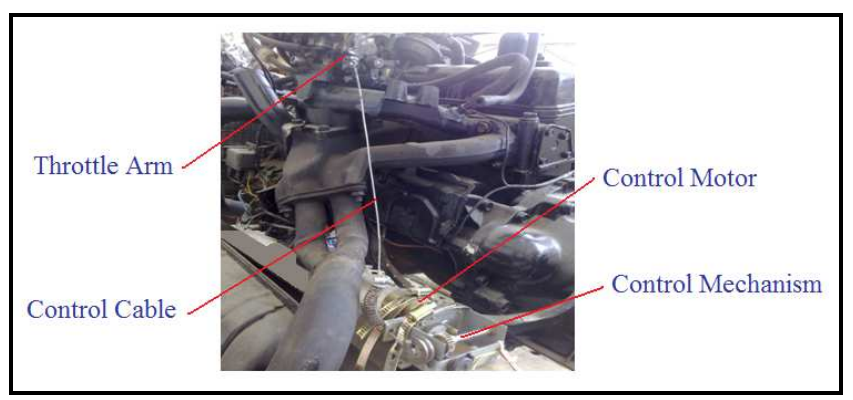

Fig 13a. First view. 


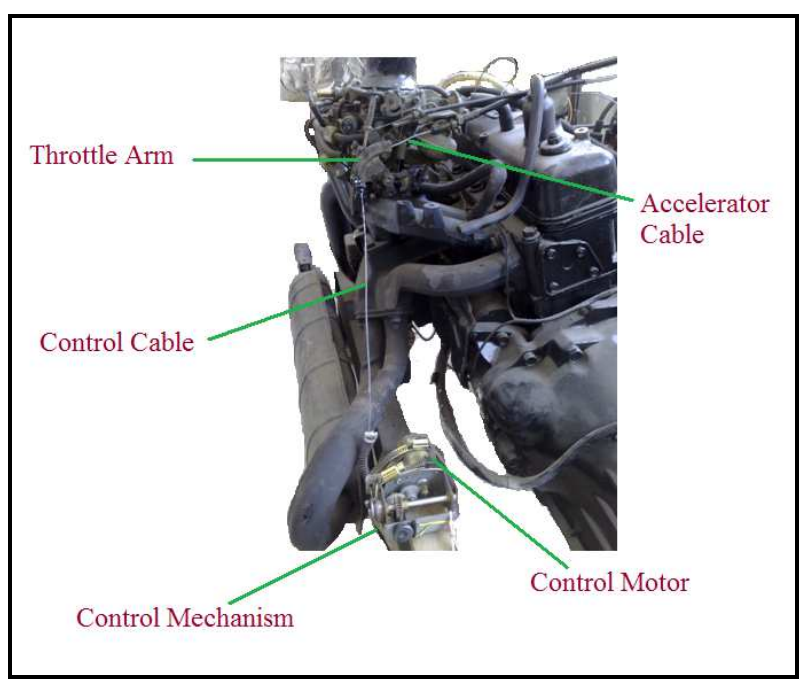

Fig 13b. Second view.

Fig 13. Two pictures of the control mechanism in its place.

The job of the control mechanism is to produce the necessary force to limit the movement of the throttle arm of the carburetor.

Figure 13 shows two pictures of the control mechanism in its place relative to the other components of the engine.

\subsubsection{Main Components of the Control Mechanism}

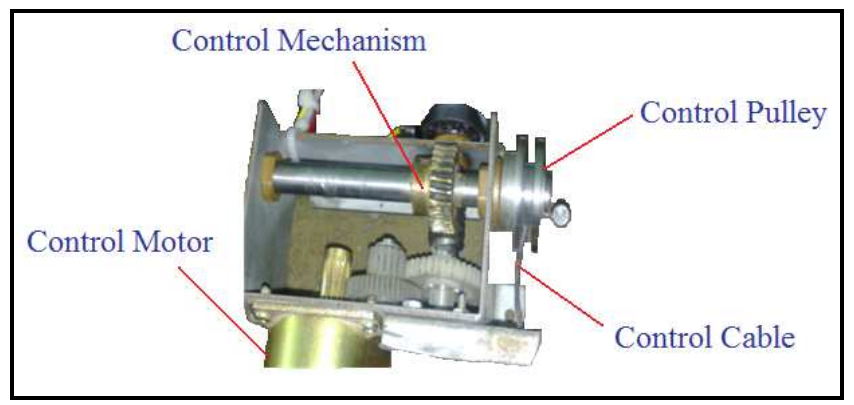

Fig 14. Main components of the control mechanism.

Figure 14 shows the main components of the control mechanism. These components can be listed as:

(1) Control motor

The function of the control DC motor is to produce the necessary torque to resist the movement of the throttle arm that obeys the accelerator cable. Figure 15 shows the DC motor that was used in the present work.

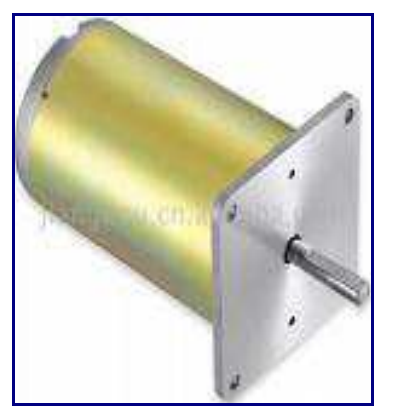

Fig 15. Picture of the used DC motor.
This $D C$ motor was selected to be suitable for the torque requirements and compatible with the control circuit. The motor is connected to the pulley through the gear train, Fig. 14.

(2) Wire-pulley assembly

The wire-pulley assembly is used to transfer the limiting torque of the motor to the throttle arm. The steel wire is welded to the pulley. The dimensions of the pulley were chosen to be suitable to the overall response of the control mechanism. Figure 16 shows a drawing of the pulley which was fabricated from steel.

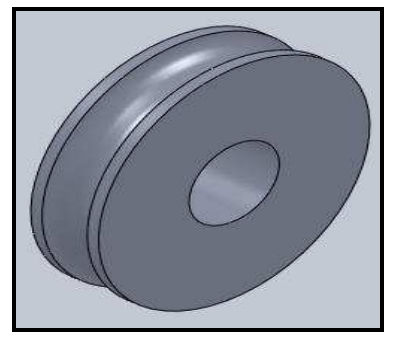

Fig 16. A drawing of the steel pulley.

\section{(3) Gear train}

A gear train was designed and fabricated to transfer the torque and movement of the $D C$ motor to the shaft of the pulley, Fig. 14. The gear train contains a combination of spur and worm gears. The overall gear ratio of the train was considered in the programming of the control circuit. Figure 17 shows a drawing of the gear train. Some of the gears were fabricated from metallic materials and others from plastic materials.

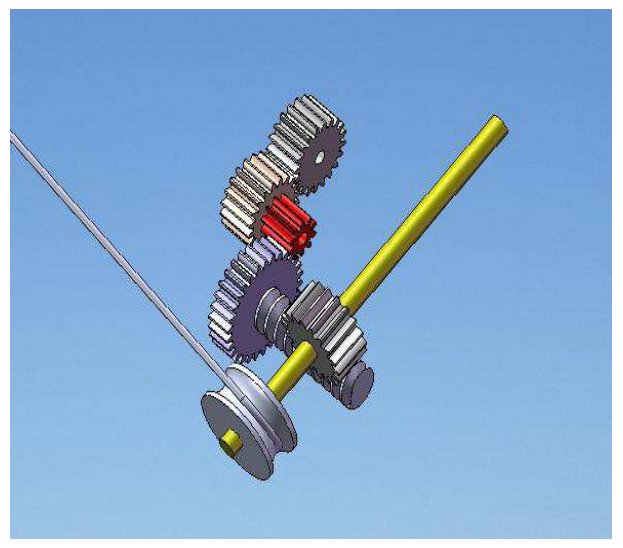

Fig 17. A drawing of the gear train.

\subsubsection{Design Steps}

The design process of the present control mechanism can be summarized in the following steps:

(1) Considering the maximum value of the force $\left(F_{r}\right)$ that is required to limit the pulling movement of the accelerator wire.

(2) Determination of the necessary pulley torque $\left(T_{p}\right)$ based on the maximum limiting force $\left(F_{r}\right)$ and the diameter of the pulley $\left(d_{p}\right)$.

(3) Calculating the overall gear reduction-ratio based on the required pulley torque $\left(T_{p}\right)$ and the maximum torque of 
the available $D C$ motors. Also, the ratio between the rotational movements of the shaft of the pulley and the shaft of the motor.

(4) Finding the required motor torque $\left(T_{m}\right)$ based on the above parameters.

(5) Final step is the motor selection from the available $D C$ motors. Suitability to the control circuit is an essential parameter in motor selection.

\subsection{Present Control Circuit}

An electronic circuit, Fig. 18, was designed and assembled to control the operation of the $D C$ motor. Thus, the necessary torque and rotation of the $D C$ motor are performed that result in resisting the movement of the accelerator cable. The final result is the speed limiting of the vehicle at different speed stages, table (2). Figure 19 shows a block diagram of the control circuit.

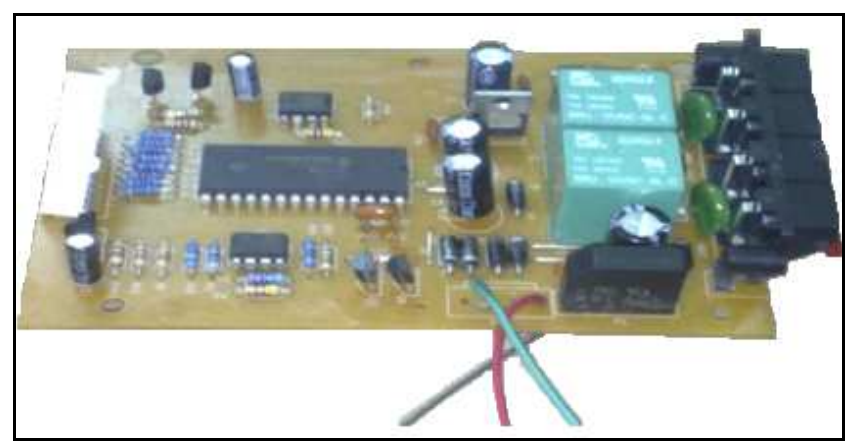

Fig 18. Picture of the present control circuit.

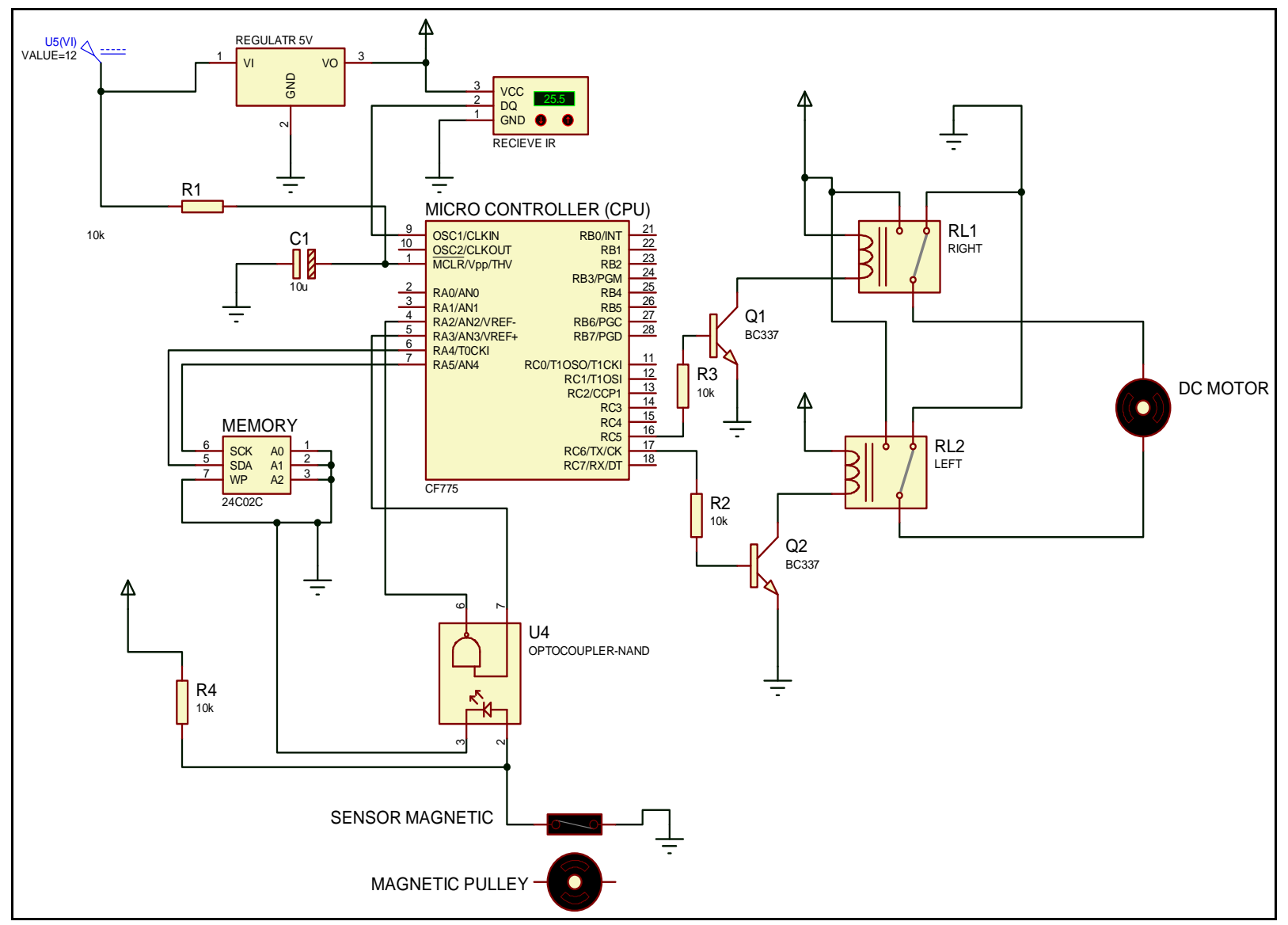

Fig 19. Block diagram of the present control circuit.

\subsubsection{Components of the Present Control Circuit}

The main components of the present control circuit, Fig. 18, can be listed as:

1. Remote-control unit: It sends the signal to the circuit receiver using infrared waves $(I R)$. The signal informs the control circuit the stage of vehicle speed as shown in table (2).

2. Receiver: It receives the signal from the remote-control unit.

3. Screen: It shows the data of the operating conditions.
4. Amplifiers: They amplify the signal that comes from the remote-control unit and convert the microcontroller command signals into the power necessary to energize the $D C$ motor windings.

5. Microcontroller: It is the most important component of the circuit. The microcontroller is a microprocessor capable of generating steps pulses and direction signals for the driver (amplifier). It is programmed to control the action of the $D C$ motor to perform the necessary operation to limit the vehicle speed at each stage of table 
(2). The microcontroller was programmed by the commercial software "MIKROBASIC" [25].

6. Two relays: The relay is a switch that is used to control a circuit by a low-power signal. Thus, the two relays are used to control the operation of the electronic circuit.

7. Transistors: A transistor is a semiconductor device that is used to amplify and switch the electronic signals and electrical power of the control circuit.

8. Memory: It is used to save vehicle speed at each stage of table (2).

9. Regulator: It keeps the voltage of the circuit at $5 \mathrm{~V}$.

10. Battery $(12 \mathrm{~V})$ : It provides the $D C$ current to the control circuit.

\subsubsection{Programming of the Microcontroller}

The microcontroller was programmed by the commercial software "MIKROBASIC, V.5.0" [25]. This software was developed as a simple programming tool of microcontrollers. Its language is similar and has characteristics of many BASIC implementations with an editing environment to allow the user to create, test and deploy BASIC programs. MIKROBASIC allows math and string operations. Also, a series of commands to control the program flow and $I / O$ operations are implemented in its interpreter engine. Generally, the software disk contains two binaries: "based.exe" and "mbasic.exe" and a set of example programs. The binary "based.exe" is the editor environment and can be used to edit and run MIKROBASIC programs. The binary "mbasic.exe" is the actual interpreter engine and it is necessary to run the developed programs. The software engine is automatically called by the editor environment. Such functionality makes very easy to develop and test applications inside the editor environment.

\subsubsection{Operation Steps of the Speed Control System}

The automotive speed control system can be operated by carrying out these steps:

1. Switching on the electronic circuit.

2. Pressing one of the buttons of the remote-control unit. Every button represents specific vehicle velocity for the engine, table (2).

3. The signal is received to the electronic circuit by the receiver and amplified by the amplifier.

4. The microcontroller compares the previous value of speed that is stored in the circuit memory with the new value that was received from the remote-control unit.

5. As a result of this comparison, the microcontroller gives the correct order to the $D C$ motor to rotate by the proper amount. This order is given based on the pre-programming of the microcontroller.

6. The motion is transferred to the shaft of the pulley through the gear train.

7. The pulley rotates to take a new position to fix the speed of the car. The rotation may be either clockwise or anti-clockwise to increase or decrease the resistance $\left(F_{r}\right)$ to the accelerator cable at the throttle arm.

8. The microcontroller checks the new position and makes necessary adjustments until reaching the correct pre-set position.

\subsubsection{Important Remarks on the Present Control System}

There are some important remarks that have to be recorded concerning the present control system, namely:

(1) The present speed control system was successfully implemented and tested. Careful observation of the operation of the control system was paid. The control system succeeded in limiting the engine speed according to the pre-set vehicle-speed stages of table (2).

(2) The signal of the remote-control unit that is used in the present model is a symbol of the external control signal to the vehicle speed control system. The infra-red (IR) signal is used for the demonstration of the idea of the speed control system. In real-life applications the control signal can be received from the control transmitter on the road itself or directly from satellites. This control signal is most likely to be a radio frequency $(R F)$ signal.

(3) A stepper motor is a good choice whenever controlled movement is required. It can be used with advantages in applications where controlling of rotation speed, speed and position is needed. However, we found that the stepper motor torque is weak to overcome the force of the accelerator pedal and this torque decreases with increasing the speed of the stepper motor. So, we rejected the idea of using a stepper motor in the present control system.

(4) Experiments were carried out to make sure that there was no effect of the present speed control system on the engine performance. Experiments revealed that there is no change on either the air/fuel ratio or the percentages of the exhaust components.

(5) It should be noted that the present test of the speed control system was carried out without actually loading the engine. This situation is due to the lack of suitable facility and resources to carry out such a test. Thus, we strongly recommend testing the present speed control system in real-life operating conditions. We think that the only difference is a new programming of the microcontroller to adjust for the loading conditions.

\section{Conclusions}

Based on the previous explanations and discussions, the following concluding points can be stated:

1. The present speed control system was successfully implemented and tested. The control system succeeded in limiting the engine speed according to the pre-set vehicle speed limits. Thus, the objective of the investigation was achieved.

2. Generally, the present mechanism has no noticeable bad effect on the engine performance. There is no change on either the air/fuel ratio or the percentages of the exhaust components.

3. The present proposed mechanism is simple, inexpensive 
and can be added to the engine with minimum modifications. It is suitable to be implemented in developing countries where a big number of cars still work using the conventional carburetor mechanism.

4. It is a challenging job to design and implement modifications to existing systems.

\section{Recommendations for Future Work}

Based on the present work, the following points can be recommended for future investigations:

1. Using the radio frequency $(R F)$ signal as the input signal to the control circuit.

2. Using satellite signal, based on the Global Positioning System (GPS), as input signal to the control circuit.

3. Development a new control circuit to be suitable to modern cars that have a fuel-injection arrangement.

4. Utilizing other control techniques and hardware such as neural networks, fuzzy logic, fuzzy-neural, programmable logic controller $(P L C)$, etc.

\section{Acknowledgements}

The authors would like to acknowledge Eng. M. Gameaa, Eng. M. Ghorab and their colleagues for helping in the assembly, programming, and testing of the control circuit as well as the manufacturing of the control mechanism.

\section{Nomenclature}

$\begin{array}{ll}d_{p} & \text { Diameter of the pulley } \\ T_{m} & \text { Motor torque } \\ T_{p} & \text { Pulley torque } \\ F_{r} & \text { Resistance force }\end{array}$

\section{Abbreviations}

$\begin{array}{ll}\text { ASLF } & \text { Adjustable Speed Limitation Function } \\ \text { DC } & \text { Direct Current } \\ \text { ECU } & \text { Electronic Control Unit } \\ \text { RPM } & \text { Engine rotational speed } \\ \text { GPS } & \text { Global Positioning System } \\ \text { I2V } & \text { Infrastructure to Vehicles } \\ \text { IR } & \text { Infrared Waves } \\ \text { ISA } & \text { Intelligent Speed Adaptation } \\ \text { PLC } & \text { Programmable Logic Controller } \\ \text { RF } & \text { Radio Frequency } \\ \text { RFID } & \text { Radio Frequency Identification } \\ \text { RSL } & \text { Road Speed Limiter }\end{array}$

\section{References}

[1] http://www.makeroadssafe.org/about/Pages/Issues.aspx: March 2013

[2] M. Paine, "Devices to Assist Drivers to Comply with Speed Limits", Vehicle Design and Research Pty Limited, Australian
Business No. $63 \quad 003 \quad 980 \quad 809$, January 2009, mpaineATtpg.com.au

[3] J. Pérez, F. Seco, V. Milanés, A. Jiménez, J. C. Díaz, and T. de Pedro, " An RFID-Based Intelligent Vehicle Speed Controller Using Active Traffic Signals", Sensors-Open Access Journal, ISSN 1424-8220, Vol. 10, pp. 5872-5887, 2010.

[4] U. J. Kameswari, M. Satwik, A. Lokesh, and G. V. Reddy, "A Design Model for Automatic Vehicle Speed Controller", International Journal of Computer Applications (0975 - 8887), Volume 35, No.9, pp. 19-24, December 2011.

[5] B. G. Radin, O. Park, and L. J. Vanderberg, "Maximum Vehicle Speed Limiter", United States Patent Office, No. 3,520,380, July 14, 1970. Assignee: "Ford Motor Company, dearborn, Michigan, USA".

[6] L. F. Mieras, "Maximum Engine Speed Limiter ", United States Patent, No. 3,563,219, Feb. 16, 1971. Assignee: "Ford Motor Company, dearborn, Michigan, USA".

[7] Z. J. Jania, and L. J. Vanderberg, "Maximum Vehicle Speed Limiter", United States Patent, No. 3,708,031, Jan. 2, 1973. Assignee: "Ford Motor Company, dearborn, Michigan, USA".

[8] W. A. Snell, and A. R. Fillman, "Engine Maximum Speed Limiter", United States Patent, No. 5,549,089, Aug. 27, 1996. Assignee:"Textron Inc., Providence, R. I".

[9] R. Fiske, A. Surabian, and K. Weigold, "Motor Vehicle Operator Identification and Maximum Speed Limiter", United States Patent, No. 7,757,803 B2, July 20, 2010.

[10] R. Fiske, A. Surabian, and K. Weigold, "Motor Vehicle Operator Identification and Maximum Speed Limiter", United States Patent, No. 7,959,177 B2, June 14, 2011. Assignee: "Kar Enterprises, LLC, Shrewsbury, MA, USA".

[11] F. H. Walz, M. Hoefliger, and W. Fehlmann, "Speed Limit Reduction from 60 to $50 \mathrm{Km} / \mathrm{h}$ and Pedestrian Injuries", Twenty-Seventh Stapp Car Crash Conference Proceedings (P-134) with International Research Committee on Biokinetics of Impacts (IRCOBI), San Diego, California, October 17-19, 1983.

[12] A. J. McLean, R. W. G. Anderson, M. J. B. Farmer, B. H. Lee, and C. G. Brooks, "Vehicle Travel Speeds and The Incidence of Fatal Pedestrian Collisions-Vol. I", NHMRC Road Accident Research Unit, The University of Adelaide, South Australia, for the Federal Office of Road Safety, Report No. CR146, October 1994.

[13] S. Ferguson, "Relation of Speed and Speed Limits to Crashes", National Forum on Speeding, Washington, D.C., USA, June 15, 2005.

[14] N. V. Malyshkina, and F. Mannering, "Effect of Increases in Speed Limits on Severities of Injuries in Accidents", Journal of the Transportation Research Board, No. 2083, pp. 122-127, 2008.

[15] S. Comte, "Evaluation of In-Car Speed Limiters: Simulator Study", Master Project, , Project Funded by he European Commission under the Transport RTD Program of the 4th Framework Program, Contract No. Ro-96-Sc.202, May 1998.

[16] "Learning from Others: An International Study on Heavy Truck Speed Limiters", Prepared for Transport Canada on behalf of the Council of Deputy Ministers Responsible for Transportation and Highway Safety, Canada, March 2008. 
10 Ahmed Farouk AbdelGawad and Talal Saleh Mandourah: Proposed Simple Electro-Mechanical Automotive Speed Control System

[17] "Safety Impacts of Speed Limiter Device Installations on Commercial Trucks and Buses", Commercial Truck and Bus Safety Synthesis Program, CTBSSP Synthesis 16, Sponsored by the Federal Motor Carrier Safety Administration, Transportation Research Board, Washington, D.C., 2008, www.trb.org

[18] R. J. Hanowski, G. Bergoffen, J. S. Hickman, F. Guo, D. Murray, R. Bishop, S. Johnson, and M. Camden, "Research on the Safety Impacts of Speed Limiter Device Installations on Commercial Motor Vehicles: Phase II", U.S. Department of Transportation, Federal Motor Carrier Safety Administration, Report No. FMCSA-RRR-12-006, March 2012.

[19] T. Mäkinen, and A. Várhelyi, "Field Trials with In-Car Speed Limiter", 9th International Conference Road Safety in Europe, Bergisch Gladbach, Germany, September 21-23, 1998.

[20] A. Várhelyi, and T. Mäkinen, "The Effects of In-Car Speed Limiters: Field Studies", Pergamon-Transport Research Part C, pp. 191-211, 2001.
[21] L. Duynstee, and H. Katteler, "Acceptance of Intelligent Speed Adaptation in Passenger Cars by Car Drivers", Proceedings of the 7th World Congress on Intelligent Transport Systems (ITS), Torino, Italy, 6-9 November 2000.

[22] J. M. Abraham, "Analysis of Highway Speed Limits", Department of Civil Engineering, Faculty of Applied Science and Engineering, University of Toronto, Italy, December 2001.

[23] "Speed management: A road safety manual for decision-makers and practitioners", 2008, http://www.autograde.ae/SPEED\%20LIMITER_GLOBAL.pd f : March 2013

[24] http://en.wikipedia.org/wiki/File:CarbNomenclature.jpg: March 2013

[25] http://www.mikroe.com/mikrobasic/: March 2013 